Homelessness, Urban Aboriginal People, and the Need for a National Enumeration

\author{
Dr. Yale D. Belanger \\ Associate Professor, Department of Native American Studies / \\ Adjunct Associate Professor, Faculty of Health Sciences, University of Lethbridge \\ Dr. Olu Awosoga \\ Assistant Professor, Faculty of Health Sciences, University of Lethbridge \\ Gabrielle Weasel Head \\ Independent Scholar, Calgary, $A B$
}

aboriginal policy studies Vol. 2, no. 2, 2013, pp.4-33

This article can be found at:

http://ejournals.library.ualberta.ca/index.php/aps/article/view/19006

ISSN: $1923-3299$

Article DOI: http://dx.doi.org/10.5663/aps.v2i2.19006

aboriginal policy studies is an online, peer-reviewed and multidisciplinary journal that publishes original, scholarly, and policy-relevant research on issues relevant to Métis, non-status Indians and urban Aboriginal people in Canada. For more information, please contact us at apsjournal@ualberta.ca or visit our website at www.ualberta.ca/nativestudies/aps/.

UNIVERSITY OF ALBERTA

FACULTY OF NATIVE STUDIES
Aboriginal Affairs and Northern Development Canada

Affaires autochtones et Développement du Nord Canada 


\title{
Homelessness, Urban Aboriginal People, and the Need for a National Enumeration ${ }^{1}$
}

\author{
Dr. Yale D. Belanger \\ Associate Professor, Department of Native American Studies / \\ Adjunct Associate Professor, Faculty of Health Sciences, University of Lethbridge \\ Dr. Olu Awosoga \\ Assistant Professor, Faculty of Health Sciences, University of Lethbridge \\ Gabrielle Weasel Head \\ Independent Scholar, Calgary AB
}

\begin{abstract}
The growing rate of urban Aboriginal homelessness is a concern in Canada, yet, to date, no national enumeration of the homeless community has been attempted. Consequently, policies implemented to guarantee vulnerable populations access to housing are being struck in the absence of reliable data. Obtaining good data on the prevalence of this homeless community is one step in improving our collective understanding and response to urban Aboriginal homelessness. According to our calculations, that homelessness is staggering: on any one night, 6.97 percent of the urban Aboriginal population in Canada is homeless, as compared to a national average of .78 percent. This paper highlights the academic and bureaucratic construction of homelessness while urging academics and front-line agencies to align their research agendas in order to help combat the issues that create homelessness in what is a uniquely challenging environment for urban Aboriginal individuals seeking services. The paper concludes with a series of recommendations that will assist in this matter.
\end{abstract}

\section{Introduction}

Homelessness is an acknowledged and significant problem in Canada's urban and rural communities, yet only a handful of national homeless counts have been attempted to date. As a result, there are policies related to housing and homelessness being struck in the absence of reliable data, a situation that casts doubt onto the soundness of the related systems, funding models, and supports ostensibly implemented to guarantee housing access to vulnerable populations. Admittedly, censuses of this type are lengthy, costly, and, in best case scenarios, methodologically challenging (e.g., Burnam and Koegel

1 The lead author would like to thank the following: Nathan Roth and Charley Waters for their outstanding research assistance; the four anonymous reviewers' helpful comments; and my Alberta Homelessness Research Consortium (AHRC) colleagues, Dr. John Graham (Calgary) and Giri Puligandla (Homeward Trust Edmonton), for their perceptive comments on an earlier draft, all of which improved this report substantially. The National Association of Friendship Centres (NAFC) and the Office of the Federal Interlocutor for Métis and Non-Status Indians (OFI), Ottawa, funded the research from which this article is derived (See Belanger, Weasel Head, and Awosoga 2012a).

aboriginal policy studies, Vol. 2, no. 2, 2013

www.ualberta.ca/nativestudies/aps/

ISSN: 1923-3299 
1988, Peressini et al.1995). ${ }^{2}$ No comparable efforts have been directed at enumerating the national Aboriginal homeless population, which is startling considering that the available evidence suggests that Aboriginal people are disproportionately represented in the overall homeless population. ${ }^{3}$ We contend that implementing a national enumeration of Aboriginal homeless on First Nations and in rural and urban settings is imperative, and that special attention needs to be directed toward generating improved understanding of the urban Aboriginal experience. The issues confronting all homeless populations are dire, but those facing the urban Aboriginal homeless population in particular are of mounting concern: growing numbers of urban émigrés lead to new residents integrating themselves into populations experiencing high birth and fertility rates. This quickly escalating population now represents more than 60 percent of the country's Aboriginal population, and 73.4 percent of the national Aboriginal households (NAHA 2009, 6).

This paper begins with a brief discussion about the centrality of collected data to the policy-making process and, specifically, in what has come to be acknowledged as a unique urban Aboriginal policy environment. We follow with an analysis of the available data drawn from "point in time" counts that take place in many, but not all, urban centres nationally. This is to help answer the question, "What is happening right now?" so that we may present a national level portrait of the current urban Aboriginal homeless situation. Third, we review the academic literature on urban Aboriginal homelessness and offer innovative research trajectories designed specifically to inform policy makers engaging urban Aboriginal homeless people. We close by presenting a list of recommendations that will: (1) improve our collective understanding of urban Aboriginal homelessness in general; and, (2) inform policy makers in their work.

\section{Why Count the Homeless?}

The 10-Year Plan to End Homelessness model has been heralded as the most efficient means for ending homelessness. Initiated in the United States by the National Alliance to End Homelessness, this four-element model has been adopted by 240 US and a growing

2 In August 2012 a group of Canada's leading researchers of homelessness and public officials associated with the Canadian Homelessness Research Network (CHRN) met at York University to discuss what they believed to be the emerging national research priorities as they work toward establishing a National Observatory of Homelessness in Canada. Of the four key domains to emerge, Aboriginal homelessness was identified as a primary issue in need of further research.

3 The term "Aboriginal peoples" indicates any one of the three legally defined culture groups that form what are known as Aboriginal peoples in Canada (Métis, Inuit, and Indian) and who self-identify as such. The term "First Nation" is used here to denote a reserve community or band. The term "Indian," as used in legislation or policy, will also appear in discussions concerning such legislation or policy. The term "Indigenous," as used here, does not represent a legal category. Rather, it is used to describe the descendants of groups in a territory at the time when other groups of different cultures or ethnic origin arrived there, groups that have almost preserved intact the customs and traditions of their ancestors similar to those characterized as Indigenous, and those that have been placed under a state structure which incorporates national, social, and cultural characteristics distinct from their own. 
number of Canadian communities. ${ }^{4}$ The plan's first point is telling, and sets out the process: "successful community plans are evidence-based" and "have measurable and ambitious outcomes and key milestones." Essentially, the plan's architects encourage data collection that is to be utilized in guiding our collective societal response to homelessness. In recent years, homeless censuses have become popular modes for collecting information on the number and shared characteristics of sheltered and homeless individuals, after which the information is used for program/policy and systems planning. Each census is intended to include people who were living on the streets, as well as those occupying emergency shelters or facilities offering longer-term care and support-basically, any individuals who did not have a permanent residence and who would otherwise be living on the streets. The United Nations and the Canadian government define this condition as "absolute homelessness."

As each census is methodologically dissimilar and there is no agreed-upon universal approach, policy creation occurs, consequently, in the absence of reliable data identifying the number and needs of those individuals, families, and children utilizing existing programs and services. This influences how we choose to mobilize available resources, modify existing services, and devise new supports. It also suggests that refined measures are desperately needed to determine both the scope of the problem and whether the local homeless population is increasing or decreasing. Nobles (2000) has argued that these types of data speak to policy effectiveness, and ultimately to program responsiveness, even if the process also reflects a form of "meaning making" that forges a specific social reality that also guides policy makers. It further acts to legitimate what Andersen (2008) describes as social equivalences between individual citizens within nation-states, which inevitably shapes official recognition and scientific validity. Despite the inherently political motivators associated with any census, and the fact that reflections of social reality often lead to the corresponding production of a specific social reality (Alfonso and Starr 1987), these types of data sets remain fundamentally important tools in guiding the formation of policy decisions impacting the homeless.

It is encouraging to see municipal governments across the country not only embracing the 10-Year Plan to End Homelessness, but also assigning resources to conduct annual counts and censuses. One could assert that the homeless counts undertaken in major urban centres across the country to date provide satisfactory data. These tend to be annual pointin-time municipal counts of homeless persons, and are, therefore, imperfect gauges of local homeless trends. Point-in-time counts are employed uniquely by each community: they utilize different methods and definitions (although, as will be discussed below, there is room to expand and clarify how homelessness can be defined for greater inclusivity, creating more representative counts), and they tend to approach their counts at different times of the year (see, e.g., Williams 2011; Koegel, Burnam, and Morton 1996; Cordray and Pion 1991). Further complicating an already fragile process is the invisibility of Aboriginal homeless persons, or the kind of hidden homelessness that makes it difficult to determine how many people are currently affected or how to respond with programs and supports

4 No inventory currently exists to show what cities and provinces have adopted the 10-Year Plan or Housing First as guiding policy structures. Accordingly, we also do not know whether or not these approaches are successful, and how to alter existing constructs to better represent homeless populations. 
(Distasio et al. 2005). It is estimated that upwards of 80 percent of the total homeless community is invisible (e.g., couch surfing, intentionally living apart from mainstream populations) and thus inaccessible to census enumerators (Raising the Roof 2004). By relying heavily on known contact points that may or may not be accessed by all homeless people, these methods underestimate the number of homeless people orbiting these sites. And, as Hulchanski $(2000,2)$ reminds us, "Point-in-time counts of the unhoused in a community focus on individuals affected by the problem, rather than the problem itself."

Finally, how we operationally define "Aboriginal" adds to the confusion. For instance, the term "Aboriginal people" indicates any one of the three legally defined categories of Aboriginal peoples in Canada (Métis, Inuit, and Indian) and who self-identify as such. The term "First Nation" is often used to denote a reserve community or band (even if no legal definition exists). The term "Indian," as used in legislation or policy, also appears in debates concerning such legislation or policy. Statistics Canada measures Aboriginality in four different ways: ethnic origin; Aboriginal identity; Registered or Treaty Indian; and member of an Indian Band or First Nation. Most importantly, it distinguishes between Aboriginal ancestry and Aboriginal identity. Aboriginal ancestry measures Aboriginality through a self-declaration of ancestry, whereas Aboriginal identity asks individuals if they self-identify as Aboriginal (First Nations, Métis, or Inuit). Moreover, individuals are given the option of identifying with more than one category; for example, one might declare oneself to be both First Nations and Métis. Aboriginal for our purposes can be defined according to policy guidelines, which influence urban and rural community members who also tend to identify along such lines. During a census, after asking if one is Aboriginal, greater clarity can be sought by inquiring about who self-identifies as First Nations, Métis, or Inuit. If the individual declines to elaborate, at the very least surveyors have a sense of how many Aboriginal people they are in contact with.

The point-in-time counts, while demonstrably problematic, nevertheless offer us insights about a diverse community that has come to include families, women and children, youth, and (increasingly) multi-family and multi-generational homes. As Hulchanski (2000) reminds us, the homeless population is a heterogeneous grouping displaying unique pathways to homelessness or homeless experiences.

\section{Defining Homelessness}

We need to define homelessness before proceeding further, as this definition has an influence on our measurement format. But how do we determine who precisely is homeless? Menzies (2005) suggests that current definitions of homelessness stress the physicality of the term relative to actual shelter, and do not address homelessness as it affects Aboriginal people. Alternately, he contributes a new definition: "the resultant condition of individuals being displaced from critical community social structures and lacking in stable housing" (8). The Canadian Parliamentary Research Branch (CPRB) has tackled these vexing questions with little success and, in lieu of one specific definition, has opted to generate three different meanings for "homeless," but all are deemed essential categories that identify people as belonging to a certain "kind" of homeless population (Casavant 1999). First, there are the chronically homeless, or individuals who live on society's margins and 
who frequently face problems of drug or alcohol abuse or mental illness. Second are the cyclically homeless, or individuals who have lost their dwelling as a result of their changed situation. These individuals intermittently utilize safe houses or soup kitchens, and their numbers regularly include women escaping family violence, runaway youths, and persons who are unemployed or recently released from detention centres or psychiatric institutions. The third group is made up of the temporarily homeless, those who lack accommodations for a relatively short period, have lost their home as a result of a disaster (e.g., fire, flood), and whose economic and personal situation has been altered by family separation or loss of job (Casavant 1999).

Since the CPRB presented its three groups, various agency-specific definitions have been devised and/or proposed that employ a continuum measuring degrees of homelessness. Hulchanski (2000) is critical of this approach for, in his opinion, it enables governments to avoid taking action for anyone who may not be, by definition, homelessness. This, in turn, masks the inherently political issue of homelessness as a statistical or definitional problem (see also O'Reilly-Fleming 1993). But what does it mean to be homeless? The Canadian Homelessness Research Network (CHRN) has developed the following working classification (Homeless Hub 2012):

Homelessness describes a range of housing and shelter circumstances, with people being absolutely homeless at one end, and experiencing housing exclusion (being precariously or inadequately housed) at the other. That is, homelessness encompasses a range of physical living situations, organized here in a typology that includes:

1. Unsheltered, or absolutely homeless and living on the streets or in places not intended for human habitation;

2. Emergency Sheltered, including those staying in overnight shelters for people who are homeless, as well as Violence Against Women shelters;

3. Provisionally Accommodated, referring to those whose accommodation is temporary, and who do not have their own home or security of tenure, and finally;

4. Insecurely Housed, which describes people who are "at risk" of homelessness, and whose current economic and/or housing situation is precarious or does not meet public health and safety standards. It should be noted that for many people homelessness is not a static state but rather a fluid experience, where people's shelter circumstances and options may shift and change quite dramatically and with frequency.

Homelessness can also be categorized by duration of homelessness that includes:

1. brief homelessness (less than 30 days);

2. short-term homelessness (less than a year); and,

3. chronic homelessness (more than a year), which is more entrenched and long term.

Such periods of homelessness can be continuous in duration or episodic in which people rotate in and out of homelessness. 
Liberal definitions of homelessness like this tend not to be the norm, as the majority of the academic, government, front-line agency, and grey literature ${ }^{5}$ tends towards statistically identifying rough/street sleepers as homeless, while anecdotally alluding to other forms of homelessness (e.g., couch surfing). Consequently, the 20 percent sleeping rough are truly homeless while the remainder are classified as "hidden homeless." This classification hinders attempts at generating an accurate national homeless rate or at capturing the national urban Aboriginal rates of homelessness.

\section{Urban Aboriginal Peoples: The Policy Environment}

While establishing accurate urban Aboriginal homeless counts is vital for raising public awareness and for establishing the data sets of policy makers, we need to set out the historical and ideological contexts of federal Indian policies that continue to influence Aboriginal peoples new to the city and who are long-time residents.

Place is a personal concept central to an individual's sense of identity. Canada's history abounds with stories of colonists moving into Indigenous territories and claiming permanent homeland status. Once permanently settled, community leaders frequently disregarded Aboriginal regional contributions in settlements many of which grew into modern cities (see, e.g., Mumford 1938). New settler-informed norms developed to guide the emergent political class pursuing community-building initiatives. Many leaders noted Aboriginal peoples repeatedly visiting their communities for health care and to search

5 As Alberani et al. have stated,

Grey Literature (GL) covers a wide spectrum of nonconventional documents. The following are some major GL categories as grouped [for this study]:

- reports-including preprints; preliminary progress and advanced reports; institutional, internal, technical, and statistical reports; research memoranda; state-of-the-art reports; market research reports; reports of commissions and study groups; etc.;

- theses;

- conference proceedings;

- technical specifications and standards;

- translations (not distributed commercially);

- bibliographies;

- technical and commercial documentation;

- official documents (issued in limited numbers)

It is often difficult to define the distinction between official publications and GL; among other definitions (ephemeral, invisible, informal, underground, etc.), GL has been recently defined as semipublished. According to the most widespread and generally recognized definition, GL is all that nonconventional material which is "not available through the conventional, commercial distribution channels." Yet, it must be remembered that in some countries (e.g., the United States and the United Kingdom), there are long-established distribution agencies that make it possible to obtain GL on request and for payment. In other countries, where there is no centralized agency for the distribution of GL, it is not as easy to obtain and to retrieve the same material $(1990,358)$. 
for economic opportunities, but rarely considered allowing visible municipal Aboriginal participation to become an active aspect of their local development plans. In response, "municipal-colonialism" materialized in many regions across Canada, which Stanger-Ross (2008) describes as the implementation of city-planning processes purposely designed to manage Aboriginal peoples in urban settings (see also Belanger forthcoming).

Many of the same attitudes that had previously resulted in Aboriginal peoples' physical isolation on reserves were now being employed by city fathers across the country to encourage urban Aboriginal exclusion. "Municipal-colonialism" had many of the same attitudes that resulted previously in the physical isolation of Aboriginal peoples on reserves, and was the mind set of city fathers as they encouraged urban Aboriginal exclusion. Arguably, these trends continue today, which Windsor and Mcvey (2005) see as extremely problematic, since forced relocation and voluntary relocation to escape damaging attitudes negatively impacts interpersonal relationships, and has been shown to arrest personal and collective identity development. Many urban Aboriginal people nationally have either overcome or learned to manage these disparate forces, and have established unique municipal social and cultural spaces they call home. Yet, ironically, the already difficult task of community building is aggravated by the destabilizing nature of being unwelcome in one's own lands (see Weasel Head 2011; cf Abele, Falvo, and Hache 2010; Christensen 2012; Ruttan, Laboucane-Benson, and Munro 2010). As Andersen (2002, 20) notes, Aboriginal people "have created new and distinct communities while concomitantly creating new cultural norms, adapting, as we have always done, to the material circumstances around us." Yet the non-Aboriginal majority still clings to the belief that cities remain alien environments to Aboriginal peoples, who are better suited to rural lifestyles even though most large cities have a long history of Aboriginal urbanization and growing interaction between urban Aboriginal and municipal leaders (e.g., Belanger and Walker 2009; Malloy 2001; Nelles and Alcantara 2009). Unfortunately, for the most part, municipal and provincial politicians have capitalized on this perceived incompatibility to legislatively abandon urban Aboriginal peoples, who are obliged to forge ahead in bureaucratically, and often socially, hostile environments (Forsyth and Heine 2008; Peters 1996),

Consequently, cities can be considered colonial environments that perpetuate binaries that highlight who is an insider/outsider and citizen/other ( $c f$ Furniss 1999), where urban Aboriginal people, accordingly, become and remain permanent outsiders. Countering this stereotype is a growing literature highlighting urban Aboriginal adaptability and how meaningful urban space has become to many Aboriginal peoples' identities (e.g., Awad 2002; Belanger et al. 2003). Peters $(2005,393)$ in particular as argued that there exists within the urban Aboriginal community "a sense of belonging, active household assistance networks, and the growing presence of self-governing institutions" (see also Peters 2004). This growing literature puts into dispute earlier assertions by Richards (2001) that Aboriginal peoples were more apt to live in socially and economically poor neighbourhoods than nonAboriginal individuals. Positive social reproduction is, nonetheless, dependent on more than local community support-it is reliant on equitable access to resources and the ability to participate in local policy development (e.g., Belanger and Walker 2009; Prentice 2007; Sookraj et al. 2010), something that in most cases continues to elude urban Aboriginal peoples. 


\section{Urban Aboriginal Homelessness: A Quantitative Perspective}

The causes and impacts of urban Aboriginal homelessness are difficult to quantify and evaluate because our understanding of these phenomena is informed by assorted anecdotal evidence consisting of front-line worker observations; and by various and methodologically disparate municipal homelessness censuses, along with the associated municipal and academic reports examining these trends (Belanger, Weasel Head, and Awosoga 2012a). Notably, academic and bureaucratic interest in urban Aboriginal homelessness has substantiated many of our assumptions, which in turn (as discussed below) has stimulated a growing literature base that offers insights into topics ranging from the effect of intergenerational trauma on homelessness (e.g., Menzies 2007) to how unique notions of homeland influence individual perceptions of what it means to be homeless (e.g., Weasel Head 2011, Christensen 2011). Two specific schools of thought have also emerged that identify the cause and effect of urban Aboriginal homelessness. One is derived from front-line, worker-collected data utilized for municipal policy development, and the second school is found in the researcher-driven academic literature, which is often developed according to personal interest, rather than with the intention of informing policy or support services (i.e., outcome-oriented. One of this paper's key purposes is to elaborate upon the evident similarities and differences of both schools while discussing how to develop research agendas that are able to partially reconcile their perspectives.

Before engaging in further discussion, it is imperative that we first establish a rough baseline underscoring national rates of urban Aboriginal homelessness for analytical purposes. Figure 1 is based on a review of homeless counts undertaken in major urban centres nationally during the last decade, and identifies the presence of significant Aboriginal homelessness in large Canadian cities. Please note that an exhaustive search was conducted for online reports and other data sources.

Not all large urban centres are represented, or even a modest sample of medium-sized urban centres, and this makes generating comparative and regional research difficult. Even so, it is apparent, according to the foundational graph in Figure 1, that urban Aboriginal homelessness is endemic in Canada. Front-line workers have known this for years, but there are additional trends of note. For example, there are high rates of urban Aboriginal homelessness in the Prairie regions: nine of the eighteen cities in the figure fall in this region. We would classify Thompson (MB) and Wood Buffalo (AB) as northerly communities, where urban Aboriginal homelessness is also extremely high, based on the Yellowknife (NWT) data. The northern urban Aboriginal homeless rates in the figure could be expected due, in part, to a harsher climate there than in the south, which leads to a reduced ability to construct efficient housing stock, which then results in more overcrowding, and then to homelessness, both by definition and in actual living conditions (Belanger, Weasel Head, and Awosoga 2012b). 
FIGURE 1: Urban Aboriginal Homeless as Percentage of Overall Homeless Population, Select Canadian Cities $^{6}$

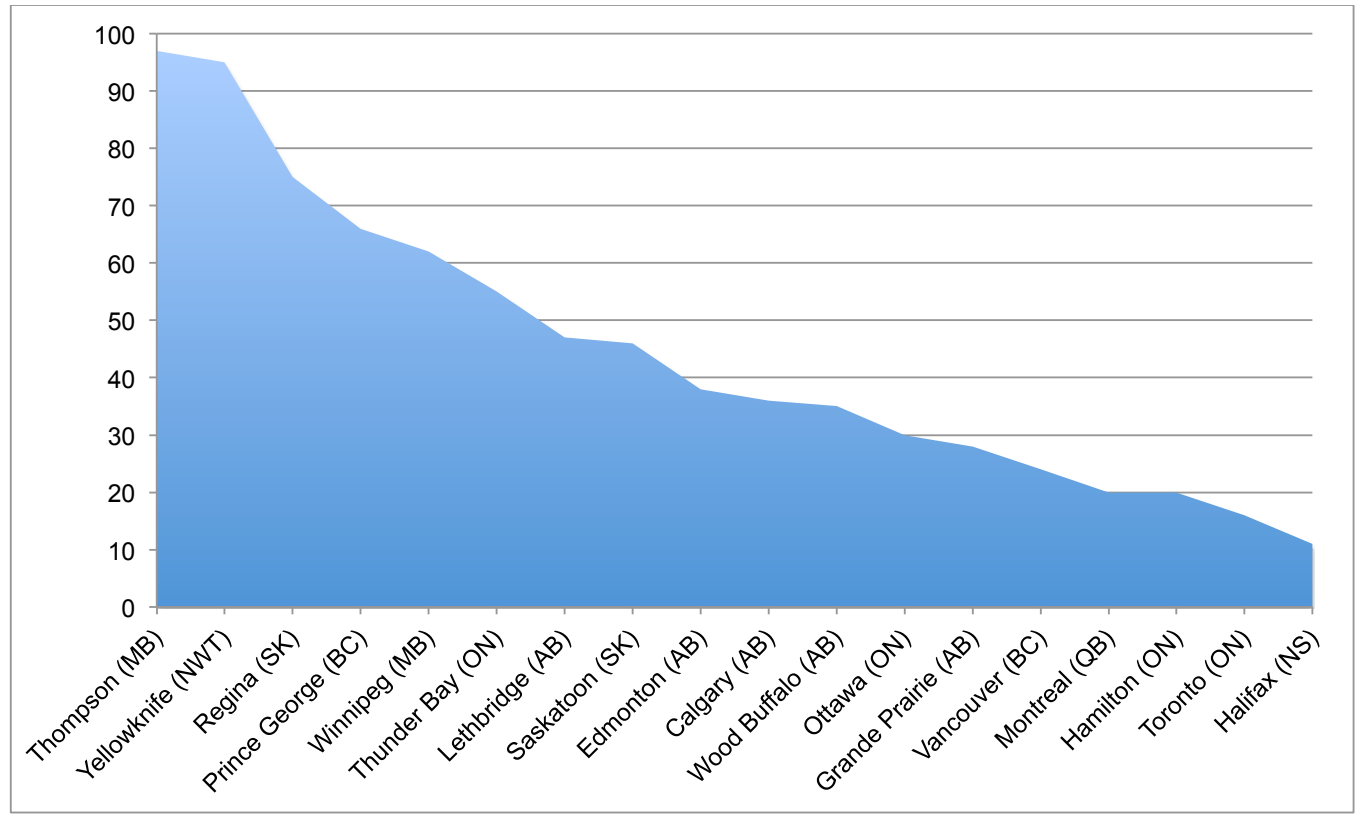

Another important trend is the lower percentage or urban Aboriginal homeless in larger centres such as Toronto (ON), Hamilton (ON), Ottawa (ON), Halifax (NS), and Vancouver (BC). However, these lower percentages are misleading. In Toronto, for example, urban Aboriginal homeless individuals make up 16 percent of the overall homeless population. When compared to Regina's 75 percent, it would appear that Toronto's homeless intervention programming is more effective. In real numbers, however, Toronto's total urban Aboriginal homeless population is roughly 4,361 people as compared to Regina, which has 2,550. Moreover, as seen in more detail in table 1, it is apparent that urban Aboriginal homelessness is not specifically the Western problem it is frequently identified as, but is evident in Ottawa, Toronto, and Yellowknife also.

6 The following reports were referenced in constructing this table: Urban Aboriginal Strategy Projects, 2009-2010 (Canada 2010); Homelessness in Yellowknife: An Emerging Social Challenge (Falvo 2011; Metro Vancouver Count Finds Same Number of Homeless But More People Using Emergency Shelters (Greater Vancouver Regional Steering Committee on Homelessness 2011); On Any Given Night: Measuring Homelessness in Hamilton (Hamilton 2006); Dealing Effectively with Aboriginal Homelessness in Toronto: Final Report (Jim Ward Associates 2008); Feeling Home: Culturally Responsive Approaches to Aboriginal Homelessness (McCallum and Isaac 2011); Homelessness Among Montreal's Aboriginal Population (National Coalition of Men 2006); Homelessness and Housing in Saskatoon (Saskatoon Housing Coalition 2008); and A Pan-Northern Ontario Inventory of Homelessness Problems and Practices: Position Paper (Stewart and Ramage 2011). 
TABLE 1: Urban Aboriginal Peoples as Percentage of Homeless, Percentage of City and Aboriginal Population, Selected Canadian Cities, 2006

\begin{tabular}{|c|c|c|c|c|}
\hline City & $\begin{array}{c}\% \text { of Aboriginal } \\
\text { People as City's } \\
\text { Homeless } \\
\text { Population }\end{array}$ & $\begin{array}{c}\% \text { of Aboriginal } \\
\text { People as } \\
\text { City's } \\
\text { Population }\end{array}$ & $\begin{array}{c}\% \text { of Aboriginal } \\
\text { Population as } \\
\text { Aboriginal } \\
\text { Homeless }\end{array}$ & $\begin{array}{c}\text { Estimated } \\
\text { Numbers of } \\
\text { Urban Aboriginal } \\
\text { Homeless } \\
\text { People } \\
\end{array}$ \\
\hline Thompson (MB) & 97 & 24 & $\mathrm{n} / \mathrm{a}$ & $\mathrm{n} / \mathrm{a}$ \\
\hline Yellowknife (NWT) & 95 & 11 & 21.7 & 889 \\
\hline Regina (SK) & 75 & 9 & 14.9 & $2,550^{*}$ \\
\hline Prince George (BC) & 66 & 11 & 8.2 & 693 \\
\hline Winnipeg (MB) & 62 & 10 & 1.6 & 1,085 \\
\hline Thunder Bay (ON) & 55 & 8 & $\mathrm{n} / \mathrm{a}$ & $\mathrm{n} / \mathrm{a}$ \\
\hline Lethbridge (AB) & 47 & 4 & 2.5 & 99 \\
\hline Saskatoon (SK) & 46 & 9 & 0.8 & 171 \\
\hline Edmonton (AB) & 38 & 5 & 1.8 & $912^{*}$ \\
\hline Calgary (AB) & 36 & 2 & 19.7 & 5,105 \\
\hline Wood Buffalo (AB) & 35 & 12 & 1.4 & 112 \\
\hline Ottawa (ON) & 30 & 2 & 18 & 2,233 \\
\hline Grande Prairie (AB) & 28 & 9 & 5.5 & 239 \\
\hline Vancouver (BC) & 24 & 2 & 0.9 & 348 \\
\hline Montreal (QC) & 20 & 0.5 & 3.8 & 633 \\
\hline Hamilton (ON) & 20 & 6 & 9.7 & $739^{*}$ \\
\hline Toronto (ON) & 16 & 0.5 & 17.3 & 4,361 \\
\hline Halifax (NS) & 11 & 1 & 3.9 & 189 \\
\hline
\end{tabular}

Source: Statistics Canada, Aboriginal Population Profile, $2006^{7}$

${ }^{\star}$ not including rough sleepers.

Digging a little deeper, we discover some additional trends. ${ }^{8}$ For the cities listed in table 1, the urban Aboriginal homeless population accounts for 29 percent of the overall homeless population in Canada. Of the total 70,200 Canadian urban homeless, 20,358

7 Ibid.

8 We must first note that generating accurate data is confounded for various reasons, ranging from an expressed Aboriginal unwillingness to engage census volunteers to the fluidity of homelessness between reserve and city (Letkemann 2004, 242; Peters and The Prince Albert Grand Council Urban Services Inc. 2009). The general lack of data is also problematic. The portrait that we are able to generate with the existing data is bleak. Anecdotally, some of the reasons for their not participating in the census include the fact many Aboriginal homeless feel they are only numbers being counted-"we are like cattle and after the count, no one bothers with us." 
are Aboriginal. ${ }^{9}$ The National Homelessness Secretariat has estimated that the Canadian homeless population exceeds 150,000 (Snow 2008), although recent academic assessments suggest that roughly 250,000 people are homeless at any given time (Segaert 2011; Laird 2007; Hulchanski et al. 2009). ${ }^{10}$ The Wellesley Institute $(2010,4)$ pushes these estimates higher and suggests that the national absolute homeless (i.e., sleeping on streets) population totals 300,000, and that upwards of 900,000 individuals live in overcrowded conditions, use shelters, and/or couch surf. Using a median 150,000 as our guide ${ }^{11}$ (a substantial majority of which is urban populations), the above analysis would suggest that there are 43,500 urban Aboriginal homeless individuals in Canada. Statistics Canada (2006) has estimated that there are an estimated 633,306 urban Aboriginal people nationally. These data would suggest that $6.97 \%$ of all urban Aboriginal people are considered to be homeless on any one night, compared with $0.78 \%$ of the mainstream population. Put another way, more than one in fifteen urban Aboriginal people are homeless, compared to one out of 128 non-Native Canadians. This means that urban Aboriginal people are more than eight times likely to be or become homeless than non-Native urban individuals.

What we are unable to determine from a simple statistical profile such as this are fundamental trends by which to formulate responsive policies. For instance, the data utilized to generate figure 1 does not provide a detailed demographic overview of what it means to be urban, Aboriginal, and homeless. Gender and age trends are not apparent, and the figure data does not speak about the reasons leading to the current episode of homelessness. It is impossible to highlight the level of individual movement, whether individuals are experiencing hyper-mobility between reserve and city, or whether this travel is between or within communities. Further, we lack insights into the prevalence of morbidity and age-related chronic diseases; the prevalence of substance use, or the type and frequency; or, importantly, who is suffering from which various disorders. Issues such as personal immobility or history of incarceration also inform the programming devised to decrease the different pathways to homelessness. While it does provide us with a statistical snapshot of some of the more obvious trends, what is lacking is the context, or more importantly, the data on the number and shared characteristics of urban Aboriginal individuals who are sheltered and homeless that are needed if we are to properly develop program/policy and systems planning.

9 These data reflect only those who were counted in recent censuses. They do not account for rough sleepers, which it is estimated make up fully 80 percent of the homeless population on any one night in Canada.

10 It is our conclusion that these figures are not meant to represent point in time counts but are, rather, annual estimated figures. This once again supports our argument for a national census of urban Aboriginal homeless (and all homeless for that matter) as a means of establishing a baseline from which to conduct analyses and establish responsive policies.

11 Although we argue that a disconnect is evident in terms of how front-line workers and academics present the issues, and as such for greater communication leading to combined research efforts, we determined that the 150,000 median point (one generated by an academic) was the appropriate starting point for our analysis; there is a new study by Segaert that looks at Homeless Individuals and Families Information System (HIFIS) data, and concludes that there are about 150,000 unique individuals who are homeless in a given year. 


\section{Urban Aboriginal Homelessness: The Academic Context}

Increased academic attention has been paid to Aboriginal homelessness in general, and urban Aboriginal homelessness more specifically, in recent years, and our overview of the literature highlights some impressive work. Most of it, however, has been developed in an unsystematic way and frequently fails to resonate with the goals of front-line agencies (Kovacs-Burns and Richter 2010). We would suggest that a "disconnect" is evident in terms of how field workers conceptualize homelessness research in comparison to how it is academically understood. Front-line workers tend to establish statistical profiles that explore the pathways to homelessness, along with the associated health and social issues. In almost every case the profiles are developed to identify population-specific issues and challenges while providing local advisory and municipal officials with the data needed to acquire population-specific funding and, thereby, ensuring appropriate programming. Academics tend to toward the conceptual, and while this work is insightful, it is oftentimes impenetrable to the layperson. The community and the academy have had a historically uneasy relationship, a fact that frequently underlies the difficulties academics, municipal politicians, local advocacy groups, and active community members face when trying to establish collaborative research. These difficulties may never be resolved.

All the same, it is vital to identify some prevalent literary themes to identify sites of common interest later, and to pursue complementary research in instances where synergy appears nonexistent. The following sections identify three main themes: pathways, urbanized peoples and mobility, and policy. Each is evaluated to determine how homelessness has, in part, been academically framed.

\section{Pathways to Homelessness}

Pathways to homelessness are, in simple terms, the individual societal and systemic forces leading to homelessness. Determining, and then ultimately tracking and assessing, these pathways is a difficult chore. The task demands the assessor make insights into how individuals and families navigate existing social services intended to alleviate homelessness, and how barriers, in turn, impede their progress towards securing permanent housing. Assessments of this type can lead to identifying best practices and the implementation of policy interventions and social supports designed to assist individuals and families to overcome these barriers. Anderson $(2001,1)$ concludes, "The notion of pathways through homelessness is central to a full understanding of the nature of homelessness," adding that this understanding offers "possibilities for alleviating homelessness." Unfortunately, as she further contends, "there has been only limited research which has examined homelessness as a dynamic process concerned with how people do or do not gain access to suitable, affordable housing - and how the housing process interacts with other socio-economic processes" (Anderson 2001, 1). The reasons offered to explain Aboriginal homelessness are diverse (see, e.g., Beavis et al. 1997; Kramer and Barker 1996). The urban Aboriginal homeless experience differs from that of mainstream Canadians due to a convoluted policy environment predicated on assumptions of cultural inferiority and forced societal participation (Beavis et al. 1997; Belanger, Weasel Head, and Awosoga 2012b). An additional aggravating factor is the connection that Aboriginal homeless have to colonization 
(Menzies 2007). Furniss (1999) asserts that dominant Euro-Canadian society celebrates Canada's settlement by glorifying a "frontier past" and Native peoples' subjugation. Canada's colonial history includes, notably, the institutions of residential schooling, child welfare, intergenerational trauma, and processes of systemic bias, which have exacted a tremendous intergenerational toll on Aboriginal families (Dion Stout and Kipling 2003; McKenzie and Morrissette 2003; Whitbeck et al. 2004).

The overt and subtle systemic dynamics that are inherent to large government bureaucracies also tend to exacerbate policy inequities by stimulating concentrated poverty levels amongst Aboriginal peoples. This, in turn, has a profound impact on homeless rates (Beavis et al. 1997). Low urban Aboriginal socio-economic indicators, such as income and education, are evidence of these trends (Newhouse and Peters 2003). The consequential welfare dependency leads to assertions of lack of motivation ${ }^{12}$ and an added cause of homelessness (Sider 2005). Just as how society tends to portray all homeless individuals, Aboriginal homelessness is conceived of as an individual problem and remediable through personal initiative and effort. However, one needs to reflect on the impact of historic Indian policies that resulted in impoverished conditions and criminalized Aboriginal behaviours, and whether contemporary policies influence urban Aboriginal homeless trends (Pate 2006). The release of an already disproportionately represented group of Aboriginal exoffenders from correctional institutions and halfway houses is a cause for concern, as these individuals frequently return to urban communities lacking basic accommodations (Brown et al. 2007). Homelessness and incarceration, then, suggest social unrest originating in colonial trauma.

Other socioeconomic factors affecting urban Aboriginal housing stability include low incomes, landlord racism, social disruption resulting from issues related to overcrowding and addictions, and the ongoing search for more acceptable and affordable accommodations. These factors impact future generations in diverse ways. For example, frequent moves and school changes have been shown to disrupt children's school performance in ways that may perpetuate poverty (Clatworthy 2008; Kissoon 2001). Brown et al. (2007) found that several of the Aboriginal youth in their study related a family history of homelessness; an ingrained belief that temporary living situations were normative; concerns regarding personal safety related to homelessness; a lack of sufficient autonomy; and the need for support networks. Another factor leading to youth homelessness is sexual abuse (Beavis et al. 1997; O'ReillyFleming 1993; Serge 2005). It has been suggested that cultural connection for homeless Aboriginal youth is a key factor in healing and recovery, as disconnection leads to street entrance, and the need to reconnect to healing (Baskin 2007; Brunanski 2009; Ruttan, Laboucane-Benson, and Munro 2008).

Racism is a contentious issue, especially in conservative communities where members work at projecting tolerance (Fiske, Belanger, and Gregory 2010; Kingfisher 2007). Evidence from Winnipeg and Thompson, for instance, highlighted discrimination against Aboriginal people in the housing rental market (Corrado Research and Evaluation Associates Inc.

12 Admittedly the language here is challenging. From a more practical perspective, lack of motivation, for example, is a by-product of other systemic forces. It is difficult to attempt to change something when one cannot see the relevance, or the results. 
2003; Mochama 2001). Conclusions like these remain difficult to act upon when nationally "the extent and seriousness of discrimination against Aboriginal people, and the impact of this on homelessness, are hard to measure" (Beavis et al. 1997, 10; see also Barsh 1997; Belanger 2007; CMHC 2003; Carter and Osborne 2009; Cohen and Corrado 2004). Under these conditions, the individual ability to become a homeowner is undermined, as is the possibility of securing affordable and suitable rental accommodations. Multi-family and multi-generational households emerge, which frequently leads to high-density living conditions, which leave the residents, by definition, homeless. A high proportion of individuals and families utilize both temporary and permanent shelters, or sleep rough with limited opportunities. Studies show that Aboriginal homeless present higher levels of substance abuse (Beavis et al. 1997; Belanger 2011b; Kingfisher 2005; Westerfelt and Yellowbird 1999). The prevalency of alcohol and drug abuse is often higher in reserves, and the behaviors remain upon moving to the city (Beavis et al. 1997). Kingfisher (2007) has confirmed that many people tend to associate Aboriginal people (males in particular) with alcoholism or, at the very least, as predisposed to substance abuse. Once again, according to contemporary norms, these outcomes are deserved for those who are purveyors of their own misery (Walker 2005).

Colonialism (and its neo-colonial derivative) informs mainstream Canada's understanding of Aboriginal people (see, e.g., Francis 1992, Saul 2008), and its connection to homelessness deserves our attention. As Menzies $(2005,68)$ has proposed, the historic features of colonialism that labeled Aboriginal people as deviant and culturally backwards planted the "seed of trauma" in Aboriginal communities that has "left a lasting legacy of dependency for many individuals and communities" (see also Ruttan, Laboucane-Benson, and Munro 2008). This connection has been inadequately explored, despite the suggested relationship between the subjugation and trauma of colonial policy and homelessness. Notably, these trends are not specific to the urban environment, for reserve poverty and abysmal housing conditions regularly force Aboriginal people lacking appropriate shelter into the cities in search of appropriate accommodations (Beavis et al. 1997). There has also been a link made between homelessness and the intergenerational trauma that has resulted from residential school experiences (Menzies 2007), even if the link has as yet to be substantiated. Picking up on this theme, Thurston and Mason's (2010) projected pathways to Aboriginal homelessness have elaborated on some of the more accepted issues driving Aboriginal homelessness, which include: (1) the Indian Act; (2) jurisdictional and coordination issues; (3) residential schools; (4) child welfare; (5) social marginalization and isolation, along with systemic discrimination and stigmatization within their own reserve communities; and, (6) individual "ruptures" or impacts/traumas. Leach (2010) has expanded on this model by suggesting that territorial displacement and high risk factors-such as systemic barriers to employment and education, discrimination/racism, and pathologies such as substance abuse-propel Aboriginal homelessness. Overall, we would argue that the state of Aboriginal homelessness is also informed by collective trauma that has superseded traditional social regulating mechanisms that, if active, could assist individuals in coping with the "individual traumas/ruptures" ( $c f$ Crop Eared Wolf 2007) 


\section{The Paradox of Urbanized Populations and Ongoing Mobility}

Urban Aboriginal homelessness emerged from the urban Aboriginal community's flourishing (Wente 2000). Today, most large cities and mid-sized municipalities boast a large, permanent, and growing Aboriginal population. And yet, academics insist on citing urban Aboriginal peoples' statistically apparent disparity to pursue what Newhouse and Fitzmaurice (2012, xvi) describe as the "study of lack," or engage in research according to what Ponting and Voyageur define as the deficit paradigm (2001, 275). This situation is, in many ways, traceable to early colonial beliefs in the perceived incommensurability of Aboriginal people and the urban environment. These beliefs still influence researchers, who fail to comprehend their predisposition to viewing Aboriginal urbanization through the deficit lens. Also, mobility is, in a pronounced way, at the heart of the literature. For instance, Aboriginal people still tend to move between cities and reserves as well as, increasingly, within cities and between municipalities, suggesting simultaneous states of permanency and itinerancy. These high levels of mobility fall into three categories: (1) residential mobility characterized by frequent moves within urban centres; (2) migration, between two different communities; and (3) churn, which is the frequent movement between city and reserve (Norris and Clatworthy 2003; Norris, Cooke, et al. 2004; Peters 2005).

But, is mobility leading to mounting housing difficulties, or is the latter driving high mobility? Arguably, both issues are interrelated and cannot be discussed independent of the other. Cooke and Belanger's (2006) work is particularly useful for determining the "whys" of mobility, for it encourages exploration of the significance of cultural connections and economic opportunities, and the variety of ongoing connections between sending and receiving communities. Memmott et al. (2006) have suggested that high mobility between places of residence is a contributing factor of Indigenous homelessness in Australia. In Winnipeg, upwards of 45 percent of research participants moved more than three times in a six-month period, highlighting the high level of residential instability (Distasio et al. 2005). The same project found that nearly one-fifth of project participants had a seasonal attachment to their home-reserve communities that, in turn, increased their frequency of movement (Distasio et al. 2005). Peters and Robilliard's (2009) research showed that their sample of urban Aboriginal people identified reserves as origins or destinations in their mobility paths over an 18-month period.

These trends resonate with Letkemann's discussion of "urban nomads" (2004) and the migratory habits of Aboriginal urban dwellers. Belanger (2007) suggests that a desire to move

quickly is a hindrance to establishing stable shelter arrangements. The ongoing effects of colonial history on homeless people's lives reveal the importance of studying the geographic pattern and scale of homeless individuals' mobility patterns (see, e.g., Christensen 2012). Aboriginal people-specifically, those who fall under the Indian Act-are unique in that they are fluid in their homelessness and have the option to "live part-time in cities and on reserves" (Letkemann 2004, 242; Peters and Robillard 2009). On the other hand, as Weasel Head (2011) has provocatively suggested, based on her work involving southern Alberta urban Aboriginal homeless, certain participants preferred a fluidity of movement reminiscent of traditional pasts. As Guimond (2003) has warned, however, the intricacy 
of urban Aboriginal identity development and the related social affiliations-neither of which are permanent or automatically transmitted intergenerationally-complicates our identification and comprehension of socio-economic characteristics and other demographic phenomena. Hypermobility's impact on homelessness remains an untested assumption even if research has acknowledged a correlation, as seen (for example) in southern Alberta (Belanger 2007; Weasel Head 2011). And, we would conclude that this mobility is deemed, unconsciously, to be a natural by-product of a previously nomadic culture that has yet to progress to a civilized permanency characterized by living in one community, as opposed to systemic racism or programmatic inequities.

This steady movement is exacting a toll on urban Aboriginal peoples. As Liberman and Frank (1980) verified, urban US Indians perceived greater levels of stress and compromised health conditions living in the city and on reservations. Similar trends are evident in Canada. Reserve-city-reserve churn remains unabated, despite proof of improved urban Aboriginal educational and income levels (Beavon and Cooke 2003; Siggner and Costa 2005). Census data highlight economic and social outcomes that are lower than the mainstream, and which appear to place urban Aboriginal at an increased risk of homelessness. A Montreal study showed a high level of psychological distress among the urban Aboriginal population as well as elevated levels of substance abuse, suggesting that Montreal was a hostile environment (Jacobs and Gill 2002). In the late 1980s, urban Aboriginal people in Saskatoon discovered their access to traditional healers was impaired (Waldram 1990). Nothing has been written lately to suggest whether this remains an issue.

But it appears that existing living conditions are no longer deemed acceptable by many, and exciting and increasingly complex dialogues probing the foundation of urban Aboriginal citizenship's variants have emerged in certain centres, led by individuals seeking to secure a degree of Aboriginal rights in urban settings (e.g., Belanger 2011b; Fiske, Belanger and Gregory 2010; Walker 2006; Wood 2003). Wilson and Peters (2005) have investigated how cities shape relationships to the land and how they influence regional kinship networks that include satellite First Nations. These ties have, ironically, helped to foster conditions that are suggestive of Aboriginal ghettoization in several, but not all, cities across Canada (e.g., Anderson 2005; Belanger 2007; Cohen and Corrado 2004). Why ghettoization does not occur in Toronto when it occurs in Regina, as an example, is an interesting question worthy of pursuit.

For those cities experiencing ghettoization, this situation should not be surprising for three reasons. First, for the last four decades, ethnicity and social class (and, more recently, gender) have been considered among the key drivers of segregation, and this increases the possibility of socio-economically depressed Aboriginal émigrés becoming isolated on the basis of class and phenotype (see, e.g., Backhouse 2001; Darroch and Marston 1971; Hou and Balakrishan 1996; Jaccoud and Brassard 2003). Secondly, urban émigrés continue to seek out and live with family members, and municipal Aboriginal neighbourhoods have evolved from this movement. Émigrés living in multi-family and multi-generational homes, and other immigrants from surrounding reserve communities moving into recently vacated local rental units, further perpetuated this process (Peters and Starchenko 2005; cf Driedger and Peters 1977). Third, these Aboriginal neighbourhoods offer respite and temporary housing to a hypermobile group who also "churn" (Norris and Clatworthy 
2003). This increases the prospect of perpetuating cycles of ghettoization, something Peters (1996) anticipated in the 1990s. Specifically she expressed alarm at the popular academic tendency to categorize Aboriginal urbanization as a social problem (the "study of lack," deficit paradigm), both in terms of urban migration's causes (i.e., better employment and education opportunities), and the alleged Aboriginal inability to adapt to urban living.

In terms of specific research domains, particular attention has been directed at examining the overrepresentation of urban Aboriginal girls and young women in the homeless population (Baskin 2007; Novac et al. 2002; Taefi and Czapska, 2007). Deiter and Otway (2001) have concluded that Aboriginal women in Canada are disadvantaged by social factors and structural inequalities, which pose barriers to their optimal wellness (see also Elias et al. 2000). Socio-economic depression is evident among women-led, singleparent Aboriginal households, which represent a large group among the poorly housed. Notably Aboriginal homeless women have often experienced childhood homelessness, which in turn normalizes homelessness (Ruttan, Laboucane-Benson, and Munro 2008). Based on current trends, one can anticipate amplified rates of urban Aboriginal female homelessness. For instance, Baskin (2007) identified Aboriginal youth as being at a higher risk of becoming homeless as compared to other youth in Canada: they are seriously overrepresented in the homeless youth population, at roughly one-third, and the rate of concealed homelessness is high. Furthermore, they experience high rates of mental health concerns, including depression and conduct disorders, both of which are confirmed pathways to homelessness (MacNeil, 2008; Whitbeck et al. 2008). Ruttan, Laboucane-Benson, and Munro (2008) established that homeless Aboriginal youth experienced poverty, health problems, systemic bias, and the effects of historical trauma, and have advised reinforcing Aboriginal community-based prevention and healing programs.

\section{Policy}

Unlike the abovementioned categories, there is little written about the policies developed to end or alleviate urban Aboriginal homelessness (Stewart 2007). Just as notably, there isn't a comprehensive overview exploring how existing policies did, and continue, to influence the perceived and actual urban misplacement of Aboriginal people. There are few national policies available that were created or intended specifically for Aboriginal peoples, which means that larger national programs tend to be the only ones available to the Aboriginal homeless. The \$753 million National Homelessness Initiative serves as an example. This three-year program was implemented in 1999 to improve community access to programs and services and to alleviate homelessness in sixty-one communities. Renewed in 2003, \$45 million was directed to the Urban Aboriginal Homelessness (UAH) module at the time. As of 2006, the Canadian Government estimated that the UAH facilitated and

developed 382 projects to provide culturally appropriate services and facilities for urban Aboriginal homeless people using an Aboriginal community planning process. Specifically, $104 \mathrm{UAH}$ projects served Aboriginal women as a subpopulation for a total approved funding of $\$ 33.5$ million or 54.6 percent of the total $\mathrm{UAH}$ funding. The total approved funding for the UAH program is $\$ 65$ million (Canada $\mathrm{n} / \mathrm{d}$ ). 
Beyond this it appears that no independent evaluations of the UAH initiative have been produced to date.

Walker (2005) contends that programs similar to the UAH, such as the Urban Aboriginal Strategy to improve federal policy development, are regressive, and ultimately fail due to a bureaucratic inability to acknowledge Aboriginal self-determination, which would involve Aboriginal participation in policy development. Instead, the strategy "seeks only to address the urgent 'problem' of Aboriginal poverty essentially managing this margin of society in pursuit of greater social cohesion," which maintains the federal government's paternalistic tendencies (Walker 2005, 410). The co-production of municipal planning involving local Aboriginal leaders could potentially open up what are now fairly exclusive policy processes to greater Aboriginal participation (e.g., Belanger and Walker 2009), but there are currently no joint federal, provincial, or municipal-Aboriginal programs aimed at specifically addressing Aboriginal homelessness and housing issues.

Interestingly programs such as Housing First, developed in New York in 1990s, have yet to be utilized to combat increasingly noticeable urban Aboriginal housing and homeless issues. Centered on finding homeless people housing and then providing additional services, Housing First's underlying tenet is that people are better able to move forward with their lives if they are housed first. This promising five-stage model encourages individual agency while offering, upon request, the treatment needed to ensure successful transition into becoming a renter. It is an adaptable program that Friendship Centres and municipal housing and homeless departments could utilize independently or in partnership. For one, individuals and families are not required to demonstrate housing readiness. Second, clients have some choice regarding the location and type of housing they receive. Third, supports are individually based and available upon request. Fourth, harm reduction seeks to reduce the risks and harmful effects associated with substance use and addictive behaviours. Finally, promoting social integration into a community requires socially supportive engagement and the opportunity to participate in meaningful activities (Gaetz 2012).

Housing First has several advantages. First of all, as demonstrated, the overrepresentation of Aboriginal people amongst the homeless population begets new and innovative strategies. Housing First is also sensitive to those individuals presenting higher than normal rates of alcohol and drug use who seek to acquire housing, a trend evident in urban Aboriginal populations. This would require additional key support workers who are trained specifically to work with urban Aboriginal peoples-in particular, entering their jobs with knowledge of the unique policy environment and socio-cultural/economic forces confronting urban Aboriginal individuals. Finally, targeted programming embracing a coordinated approach to working with urban Aboriginal peoples with the goal of improving housing opportunities and alleviating risk factors is also deemed essential. ${ }^{13}$

13 The Fred Victor Centre in Toronto is an example of another initiative that encourages community members to become actively involved in the design and delivery of programs while participating in the decisionmaking processes. 


\section{Concluding Thoughts}

The urban Aboriginal community has grown substantially in recent years, but so too has the urban Aboriginal homeless population. The inventory of reasons describing why this is occurring is long and varied, and often overwhelms policy makers and analysts. The lack of data further undermines our attempts at understanding and response. As we highlighted in figure 1, an estimated 6.97 percent of all urban Aboriginal people in Canada are considered to be homeless on any one night, based on our chosen definition of homelessness. Admittedly, our estimate is based on scattered evidence collected from an assortment of methodologically dissimilar sources. We also suggest that our estimate underestimates the total urban Aboriginal homeless population based on the knowledge that current census techniques capture roughly one-fifth of the homeless population. What is needed at this point is a methodologically rigorous national enumeration to establish the data sets required if we are to begin to fully comprehend the scope of the issues confronting the homeless, the front line workers cobbling programs and services together, and the policy makers tackling such an intricate issue.

The two schools of research we have identified at this point may appear to stand in contrast to one another but they also demonstrate great complementary potential. On the one hand, municipal officials restricted by budgetary concerns are often able to gather basic demographic data only to implement responsive policies and programs. What they do have access to, however, are the homeless populations at local shelters and those who utilize front-line agencies. In our experience, these individuals are quite willing to discuss issues of concern with researchers. Academics, on the other hand, require access to these populations if they are to pursue their work expanding on general trends and fleshing out theoretically complex understandings of the issues. Unlike municipal officials, they also have access to funding through various agencies, permitting the institution of longitudinal and long-term projects and thereby enabling a deeper understanding of the issues under study. Coming to a like mind on research projects is never an easy chore but, as established above, current trends in academic urban Aboriginal homelessness research resonate with what municipal leaders need to accomplish in their own decision-making processes, demonstrating a potential synergy of research needs. Dialogue, in this instance, is the conduit to effective research partnerships.

But, beyond expanded counts embracing more comprehensive demographics, what type of community-based research is needed that would also be attractive to academics: qualitative research exploring what it means to be urban and Aboriginal? How individuals on the street map their environment? Engaging service providers and establishing hierarchies of support within their communities would add to our understanding in substantial ways. Knowledge of how different ages groups and genders are affected is also vital for policy makers for, as it stands, existing policies-like those for single mothers, as an example-outweigh the level of existing services for the elderly or homeless males. Additional work determining the level of individual movement, whether individuals are experiencing hypermobility between reserve and city, or whether this travel is between or within municipalities is also needed. We also suggest that the existing estrangement felt by Aboriginal people from reserve social structures, families, and traditional community 
(if it does still exist) will only deepen. The level of available services and supports also demand evaluation. We lack insights into the prevalence of morbidity and age-related chronic diseases or the prevalence of substance use, type, and frequency; notably, we don't know who is suffering from concurrent disorders. Again, policy makers need to be acquainted with these trends, as well as with personal immobility issues and incarceration histories. Current counts and censuses do provide us with a statistical snapshot of some of the more obvious trends, but longitudinal research is required to offer us the context needed concerning the number and shared characteristics of urban Aboriginal sheltered and homeless individuals.

Pointing to one issue, or attempting to characterize Aboriginal homelessness according to a collection of drivers, does little more than simplify an inherently complex issue. Until we embrace a comprehensive approach driven by an agreed-upon need to improve data collection techniques, we will continue to underestimate or overlook a multitude of causes and influences leading to or exacerbating current urban Aboriginal homelessness. This, in turn, will continually impair our collective ability to respond politically. The complexity associated with Aboriginal homelessness demands more than a review of the scattered evidence. Time and energy is required regionally, provincially, and nationally to get a better sense of the context of urban (and rural) Aboriginal homelessness through the prism of history, from various policy perspectives (i.e., municipal, provincial, territorial, federal), and ongoing political and social attempts at forcing societal separation until formal assimilation occurs.

Toward this end, we endorse a number of recommendations we feel will assist in this matter:

1. formally endorse the National Aboriginal Housing Association's call for a national nonreserve housing strategy. Specifically, the Government of Canada and the provincial and territorial governments need to meet fully, in co-operation with Aboriginal people and within ten years, the need for adequate housing of Aboriginal people not living on reserves;

2. establish a Housing and Homelessness Secretariat devoted to reserve and urban Aboriginal housing and homelessness issues;

3. a comprehensive national enumeration of Aboriginal homelessness must be conducted. In its stead, a research report evaluating the existing municipal and other academic reports and data sets that explore the issues of urban Aboriginal homelessness from federal, provincial, and regional perspectives, is needed to help unpack the systemic drivers of existing difficulties;

4. the nature of homelessness needs to be explored, as does our understanding of rural Aboriginal homeless rates and its impact on urban trends;

5. greater autonomy and flexibility must be provided to Aboriginal organizations delivering programs in rural areas and to urban social housing corporations. 


\section{Bibliography}

Abele, F., N. Falvo, and A. Hache. 2010. "Homeless in the Homeland: A Growing Problem for Indigenous People in Canada’s North.” Parity 23 (9): 21-24.

Alberani, V., P. Pietrangeli, and A. Mazza. "The Use of Grey Literature in Health Sciences: A Preliminary Survey." Bulletin of the Medical Library Association 78 (4): 358-63.

Alonso, W. and P. Starr. 1987. "Introduction," in The Politics of Numbers, ed. W. Alonso and Paul Starr, 1-6. New York: Russell Sage Foundation.

Andersen, C. 2002. "Courting Colonialism: Contemporary Métis Communities and the Canadian Judicial Imagination.” Paper presented at Reconfiguring Aboriginal-State Relations, Queen's University, Kingston, ON, 1-2 November.

- - - 2008. "From Nation to Population: The Racialization of 'Métis' in the Canadian Census." Nations and Nationalism 14 (2): 347-68.

Anderson, A. 2005. "Socio-Demographic Study of Aboriginal Population in Saskatoon." Paper produced for Bridges and Foundations Project on Urban Aboriginal Housing, University of Saskatchewan.

Anderson, I. 2001. "Pathways Through Homelessness: Towards a Dynamic Analysis." Research Seminar, University of Western Sydney. www.urbancentre.utoronto.ca/ pdfs/elibrary/Anderson_Pathways-Homeless_.pdf Accessed February 5, 2013.

Awad, M. 2004. "Aboriginal Affairs." Canadian Architect (May): 53-54.

Backhouse, C. 2001. Colour-Coded: A Legal History of Racism in Canada, 1900-1950. Toronto: University of Toronto Press.

Barsh, R. L. 1997. “Aboriginal People in an Urban Housing Market: Lethbridge, Alberta.” Canadian Journal of Native Studies 27 (2): 203-14.

Baskin, C. 2007. "Aboriginal Youth Talk about Structural Determinants as the Cause of Their Homelessness." First Peoples Child \& Family Review 3 (3): 31-42.

Beavis, M. Ann, N. Klos, T. Carter, and C. Douchant. 1997. Literature Review: Aboriginal Peoples and Homelessness. Ottawa: Canada Mortgage and Housing Corporation.

Beavon, D. and M. Cooke. 2003. "An Application of the United Nations Human Development Index to Registered Indians in Canada, 1996." In Aboriginal Conditions: Research as a Foundation for Public Policy, ed. J. P. White, P. S. Maxim, and D. Beavon, 201-21. Vancouver: UBC Press.

Belanger, Y.D. 2007. "Assessing Urban Aboriginal Housing Needs in Southern Alberta." Saskatchewan Institute on Public Policy, Public Policy Paper \#51.

- _ . 2011a. "The United Nations Declaration on the Rights of Indigenous Peoples and Urban Aboriginal Self-Determination in Canada: A Preliminary Assessment." aboriginal policy studies 1 (1): 132-61. http://dx.doi.org/10.5663/aps.v1i1.10134

- - . 2011b. Lethbridge Sheltered Populations: An Overview of Current Trends, 20102011. Lethbridge: Social Housing in Action Society. 
- - - forthcoming. "Breaching Reserve Boundaries: Canada v. Misquadis and the Legal Evolution of the Urban Aboriginal Community." In Indigenous Urbanization in International Perspective, ed. E. J. Peters and C. Anderson. Vancouver: UBC Press.

Belanger, Y. D., G. Weasel Head, and O. Awosoga. 2012a. Housing and Homelessness of Urban Aboriginal People in Urban Centres. Ottawa: National Association of Friendship Centres/Office of the Federal Interlocutor for Métis and Non-Status Indians.

- - - 2012b. "Housing and Aboriginal People in Urban Centres: A Quantitative Evaluation." aboriginal policy studies 2 (1): 4-25. http://dx.doi.org/10.5663/aps. v2i1.17705

Belanger, Y. D. and R. Walker. 2009. "Interest Convergence \& Co-production of Plans: An Examination of Winnipeg's 'Aboriginal Pathways." Canadian Journal of Urban Research 18 (1): 118-39.

Belanger, Y. D., L. Barron, M. Mills, and C. McKay-Turnbull. 2003. Urban Aboriginal Youth in Winnipeg: Culture and Identity Formation in Cities. Winnipeg: Department of Culture and Heritage Canada.

Brown, J. D. Knol, S. Prevost-Derbrecker, and K. Andrushko. 2007. "Housing for Aboriginal Youth in the Inner City of Winnipeg." First Peoples Child and Family Review 3 (2): 56-64.

Brunanski, D. M. 2009. "Counselling with Aboriginal Street Youth: An Aboriginalizing Narrative Inquiry.” M.A. thesis, University of British Columbia.

Burnam, M. A. and P. Koegel. 1988. "Methodology for Obtaining a Representative Sample of Homeless Persons: The Los Angeles Skid Row Study." Evaluation Review 12 (2): 117-52. http://dx.doi.org/10.1177/0193841X8801200202

CMHC. 2003. Aboriginal Peoples of Canada: A Demographic Profile, 2001 Census. 2001 Census of Canada, vol. 96F0030XIE2001007. Ottawa: Statistics Canada.

Canada. $\mathrm{n} / \mathrm{d}$. List of issues to be taken up in connection with the consideration of the fifth periodic report of CANADA concerning the rights referred to in articles 1-15 of the International Covenant on Economic, Social and Cultural Rights (E/C.12/ CAN/5). Accessed 29 January 2013. http://www2.0hchr.org/english/bodies/cescr/ docs/canada_5threport.pdf.

Canada. 2010. Urban Aboriginal Strategy Projects, 2009-2010. Accessed 10 March 2012. http://www.aadncaandc.gc.ca/eng/1316007831303

Carter, T. and J. Osborne. 2009. "Housing and Neighbourhood Challenges of Refugee Settlement in Declining Inner City Neighbourhoods: A Winnipeg Case Study." Journal of Immigrant and Refugee Studies 7: 308-27.

Casavant, L. 1999. "Definitions of Homelessness." Government of Canada. Parliamentary Research Branch: Political and Social Affairs Divisions. Accessed December 2, 2010. http://dsp-psd.pwgsc.gc.ca/Collection-R/LoPBdP/modules/prb99-1homelessness/definition-e.htm\#DEFINITIONtxt. 
Christensen, J. 2012. “They want a different life': Rural Northern Settlement Dynamics and Pathways to Homelessness in Yellowknife and Inuvik, Northwest Territories." The Canadian Geographer-Le Géographe Canadien 56 (4): 419-38. doi: 10.1111/j.1541-0064.2012.00439.x.

_- - 2011. "Homeless in a Homeland: Housing (in)Security and Homelessness in Inuvik and Yellowknife, Northwest Territories." Ph.D. diss., McGill University, Quebec.

Clatworthy, S. 2008. "Housing need and residential mobility among urban Aboriginal children and youth." Horizons 10 (1): 91-96.

Cohen, I. M. and R. R. Corrado. 2004. "Housing Discrimination Among a Sample of Aboriginal People in Winnipeg and Thompson, Manitoba." In Aboriginal Policy Research: Setting the Agenda for Change, ed. J. P. White, P. Maxim, and D. Beavon 113-26. Toronto: Thompson Educational Publishing.

Cooke, M. and D. Belanger. 2006. "Migration Theories and First Nations Mobility: Towards a Systems Perspective." Canadian Review of Sociology and Anthropology 43 (2): 151-64. http://dx.doi.org/10.1111/j.1755-618X.2006.tb02217.x

Cordray, D. S. and G. M. Pion. 1991. "What's Behind the Numbers? Definitional Issues in Counting the Homeless." Housing Policy Debate 2 (3): 869-82. http://dx.doi.org/10 $.1080 / 10511482.1991 .9521065$

Corrado Research and Evaluation Associates Inc. 2003. Housing Discrimination and Aboriginal People in Winnipeg and Thompson, Manitoba. Ottawa: Canada Mortgage and Housing Corporation.

Crop Eared Wolf, A. 2007. "MATSIYIPÁÍTAPIIYSSINI: Káínai Peacekeeping and Peacemaking." M.A. thesis, University of Lethbridge.

Darroch, A. G. and W. G. Marston. 1971. "The Social Class Basis of Ethnic Residential Segregation: The Canadian Case." American Journal of Sociology 77: 491-510. http://dx.doi.org/10.1086/225160

Deiter, C. and L. Otway. 2001. Sharing our Stories on Promoting Health and Community Healing: An Aboriginal Women's Health Project. Winnipeg: Prairie Women's Health Centre of Excellence.

Dion Stout, M. and G. Kipling. 2003. Aboriginal People, Resilience and the Residential School Legacy. Ottawa: Aboriginal Healing Foundation.

Distasio, J., G. Sylvestre, and S. Mulligan. 2009. "Hidden Homelessness among Aboriginal Peoples in Prairie Cities." In Finding Home: Policy Options for Addressing Homelessness in Canada, ed. J.D. Hulchanski, P. Campsie, S. Chau, S. Hwang, and E. Paradis, chapter 6.3. Toronto: Cities Centre, University of Toronto. http:// homelesshub.ca/Resources/Documents/FindingHome_Full.pdf

Dreidger, L. and J. Peters. 1977. "Identity and Social Distance: Towards Understanding Simmel's 'The Stranger." Canadian Review of Sociology/Revue canadienne de sociologie 14 (2): 158-173. http://dx.doi.org/10.1111/j.1755-618X.1977.tb00339.x 
Elias, B., A. Leader, D. Sanderson, and J. O’Neil. 2000. Living in Balance: Gender, Structural Inequalities, and Health Promoting Behaviours in Manitoba First Nation Communities. Winnipeg: Centre for Aboriginal Health.

Falvo, N. 2011. Homelessness in Yellowknife: An Emerging Social Challenge. The Homeless Hub Report Series: Report \#4. Toronto: The Homeless Hub. Accessed 10 March 2012. www.homelesshub.ca/ResourceFiles/Falvo_Homelessness_Policy_Report_ finalMAY25.

Fiske, J.A., Y. D. Belanger, and D. S. Gregory. 2010. “Outsiders in Their Homeland: Discursive Construction of Aboriginal Women and Citizenship." American Indian Culture and Research Journal 34 (3): 71-92.

Forsyth, J. and M. Heine. 2008. "Sites of Meaning, Meaningful Sites? Sport and Recreation for Aboriginal Youth in Inner City Winnipeg, Manitoba." Native Studies Review 17 (2): 99-113.

Francis, D. 1992. The Imaginary Indian: The Image of the Indian in Canadian Culture. Vancouver: Arsenal Pulp Press.

Furniss, E. 1999. The Burden of History: Colonialism and Frontier Myth in a Rural Canadian Community. Vancouver: UBC Press.

Gaetz, S. 2012. Housing: Housing First. Accessed 7 May 2012. http://www.homelesshub.ca/ Topics/View.aspx?id=209\&AspxAutoDetectCookieSupport=1

Greater Vancouver Regional Steering Committee on Homelessness. 2011. Metro Vancouver Count Finds Same Number of Homeless But More People Using Emergency Shelters. Accessed 11 March 2012. http://www.orgcode. com/2011/05/24/stop-homelessness-»-2011-metro-vancouver-homeless-countfinds-same-number-of-homeless-but-more-people-using-emergency-shelters/.

Guimond, E. 2003. "Fuzzy Definitions and Population Explosion: Changing Identities of Aboriginal Groups in Canada." In Not Strangers in These Parts: Urban Aboriginal Peoples, ed. D. R. Newhouse and E. J. Peters, 35-49. Policy Research Initiative: Ottawa.

Hamilton. 2006. On Any Given Night: Measuring Homelessness in Hamilton. Hamilton, ON: Community Services. Accessed 10 March 2012. http://www. hamilton.ca/NR/rdonlyres/A85A4701-C327-459D-A66E-19D81CFA6A99/0/ OnAnyGivenNight2007.pdf

Hou, F. and T.R. Balakrishan. 1996. "The Integration of Visible Minorities in Contemporary Canadian Society." Canadian Journal of Sociology 21 (3): 307-26. http://dx.doi.org/10.2307/3341769

Hulchanski, J. D. A New Canadian Pastime? Counting Homeless People. Accessed 5 February 2013. http://www.urbancentre.utoronto.ca/pdfs/researchassociates/ Hulch_CountingHomelessPeople.pdf 
Hulchanski, J. D., P. Campsie, S. Chau, S. Hwang, and E. Paradis. eds. 2009. Finding Home: Policy Options for Addressing Homelessness in Canada (e-book). Toronto: Cities Centre, University of Toronto.

Homeless Hub. 2012. Canadian Definition of Homelessness. Accessed 6 May 2012. http:// homelesshub.ca/Library/View.aspx?id=54225\&AspxAutoDetectCookieSupport=1.

Jaccoud, M. and R. Brassard. 2003. "The Marginalization of Aboriginal Women in Montreal." In Not Strangers in These Parts: Urban Aboriginal Peoples, ed. D. R. Newhouse and E. J. Peters, 131-45. Ottawa: Policy Research Initiative.

Jacobs, K. and K. Gill. 2002. "Substance Abuse in an Urban Aboriginal Population: Social, Legal and Psychological Consequences." Journal of Ethnicity in Substance Abuse 1 (1): 7-25.

Jim Ward Associates. 2008. Dealing Effectively with Aboriginal Homelessness in Toronto: Final Report. Accessed 20 March 2012. http://www.toronto.ca/housing/pdf/ dealing_effectively_aboriginal_homelessness.pdf.

Kingfisher, C. 2005. "How the Housed View the Homelessness: A Study of the 2002 Controversy in Lethbridge.” Accessed 8 October 2008. http://intraspec.ca/ HowtheHousedViewtheHomeless.pdf.

- _ - 2007. "Discursive Constructions of Homelessness in a Small City in the Canadian Prairies: Notes on Deconstruction, Individualization, and the Production of (Raced and Gendered) Unmarked Categories." American Ethnologist 34 (1): 91 107.

Kissoon, P. 2001. "Pathways to Homelessness: Case Study of the Housing Careers of Homeless People in Toronto." M.A. thesis, York University, Toronto.

Koegel, P., A. Burnam, and S. Morton. 1996. "Enumerating Homeless People: Alternative Strategies and Their Consequences." Evaluation Review 20 (4): 378-403. http:// dx.doi.org/10.1177/0193841X9602000402

Kovacs Burns, K. and S. M. Richter. 2010. Homelessness-Related Research Capacities in Alberta: A Comprehensive Environmental Scan. 1990-2010. Accessed February 5, 2013. http://homelesshub.net/research/ahrc/environmental-scan-2010.

Kramer, B. J. and J. C. Barker. 1996. "Homelessness Among Older American Indians, Los Angeles, 1987-1989.” Human Organization 55 (4): 396-408.

Kuhn, P. and A. Sweetman. 2002. "Aboriginals as Unwitting Immigrants: Contact, Assimilation and Labour Market Outcomes." Journal of Population Economics 15: 331-55.

Laird, G. 2007. Shelter. Homelessness in a Growth Economy: Canada's 21st Century Paradox. A Report for the Sheldon Chumir Foundation for Ethics in Leadership. Calgary: Sheldon Chumir Foundation for Ethics in Leadership.

Lange, L. 2010. "Elderly People of Aboriginal Origin in Winnipeg: Their Struggle to Secure Safe and Affordable Housing." M.A. thesis, University of Manitoba, Winnipeg. 
Leach, A. 2010. “The Roots of Aboriginal Homelessness in Canada.” Parity 23 (9): 12-13.

Letkemann, P. G. 2004. "First Nations Urban Migration and the Importance of 'Urban Nomads' in Canadian Plains Cities: A Perspective from the Streets." Canadian Journal of Urban Research 13 (2): 241-56.

Liberman, D. and J. Frank. 1980. “Individuals' Perceptions of Stressful Life Events: A Comparison of Native American, Rural, and Urban Samples Using the Social Readjustment Rating Scale.” White Cloud Journal 1 (4): 15-19.

Malloy, J. 2001. "Double Identities: Aboriginal Policy Agendas in Ontario and British Columbia." Canadian Journal of Political Science 34 (1): 131-56

MacNeil, M. S. 2008. "An Epidemiologic Study of Aboriginal Adolescent Risk in Canada: The Meaning of Suicide." Journal of Child and Adolescent Psychiatric Nursing 21 (1): 3-12. http://dx.doi.org/10.1111/j.1744-6171.2008.00117.x

McCallum, K. and D. Isaac. (2011). Feeling Home: Culturally Responsive Approaches to Aboriginal Homelessness. Vancouver: Social Research and Planning Council of BC

McKenzie, B. and V. Morrisette. 2003. "Social Work Practice and Canadians of Aboriginal Background: Guidelines for Respectful Social Work.” Envision: The Manitoba Journal of Child Welfare 2 (1): 13-39.

Memmott, P., S. Long, and L. Thomson. 2003. Indigenous Mobility in Rural and Remote Australia. Melbourne: Australian Housing and Urban Research Institute, Queensland Research Centre.

Menzies, P. 2005. Orphans within Our Family: Intergenerational Trauma and Homeless Aboriginal Men. Toronto: University of Toronto Press.

- - - 2007. "Understanding Aboriginal Intergenerational Trauma from a Social Work Perspective." Canadian Journal of Native Studies 27 (2): 367-92.

Mochama, A. N. 2001. "Residential Mobility of the Urban Poor: A Study of FemaleHeaded Single Parent Aboriginal Households in Winnipeg." M.A. thesis, University of Winnipeg.

Mumford, L. 1938. The Culture of Cities. New York: Harcourt, Brace, and World.

National Aboriginal Housing Association (NAHA). 2009. A Time for Action: A National Plan to Address Aboriginal Housing. Ottawa: National Aboriginal Housing Association.

National Coalition of Men. 2006. Homelessness Among Montreal's Aboriginal Population. Accessed 18 December 2006. www.nfcm.org/projects_montreal.htm\#homeless.

Native Women's Association of Canada. 2004. Background Document on Aboriginal Women and Housing for the Canada-Aboriginal Peoples Roundtable Sectoral Follow-up Session on Housing. Accessed 6 December 2010. http://www.nwac.ca/ sites/default/files/reports/NWAC_BgPaper_e.pdf. 
Nelles, J. and C. Alcantara. 2011. "Strengthening the Ties that bind? An Analysis Of Aboriginal-Municipal Inter-Governmental Agreements in British Columbia." Canadian Public Administration 54 (3): 315-34. http://dx.doi.org/10.1111/j.17547121.2011.00178.x

Newhouse, D. and K. FitzMaurice. 2012. "Introduction.” In Well-being in the Urban Aboriginal Community: Fostering Biimaadiziwin, a National Research Conference on Urban Aboriginal Peoples, ed. D. Newhouse, K. FitzMaurice, T. McGuireAdams and D. Jetté, ix-xxi. Toronto: Thompson Educational Publishing.

Newhouse, D. and E. J. Peters. 2003. “The Way Forward.” In Not Strangers in These Parts: Urban Aboriginal Peoples, ed. D. Newhouse and E. J. Peters, 281-84. Ottawa, Policy Research Initiative.

Nobles, M. 2000. Shades of Citizenship: Race and the Census in Modern Politics. Stanford, CA: Stanford University Press.

Norris, M. J. and S. Clathworthy. 2003. "Aboriginal Mobility and Migration within Urban Canada: Outcomes, Factors and Implications." In Not Strangers in These Parts: Urban Aboriginal Peoples, ed. D. Newhouse and E. J. Peters, 51-78. Ottawa: Policy Research Initiative.

Novac, S., S. Luba, M. Eberle, and J. Brown. 2002. On Her Own: Young Women and Homelessness in Canada. Ottawa: Canadian Housing and Renewal Association.

O'Reilly-Fleming, T. 1993. Down and Out in Canada: Homeless Canadians. Toronto: Canadian Scholars Press, Inc.

Pate, K. 2006. “'If you have come here to help me ...' Why Women are in Canadian Prisons." Canadian Dimensions 40 (2): 20-22.

Peressini, T., L. McDonald, and D. Hulchanski. 1995. Estimating Homelessness: Towards A Methodology for Counting The Homeless in Canada. Ottawa: CMHC.

Peters, E. J. 1996. “'Urban' and 'Aboriginal': An Impossible Contradiction?” In City Lives and City Forms: Critical Research and Canadian Urbanism, ed. J. Caulfield and L. Peake, 47-62. Toronto: University of Toronto Press.

_-_. 2004. “Three Myths About Aboriginals in Cities.” Breakfast in the Hill Seminar Series. Canadian Federation for the Humanities and Social Sciences. http://fedcan. virtuo.ca/images/File/PDF/BOH/breakfast-peters0304.pdf Accessed February 5, 2013.

- - - 2005. "Indigeneity and Marginalisation: Planning for and with Urban Aboriginal Communities in Canada." Progress in Planning 63: 327-404. http://dx.doi. org/10.1016/j.progress.2005.03.008

Peters, E. J. and V. Robilliard. 2009. “Everything you want is there': The Place of the Reserve In First Nations' Homeless Mobility." Urban Geography 3 (6): 652-80. http://dx.doi.org/10.2747/0272-3638.30.6.652

Peters, E. J. and The Prince Albert Grand Council Urban Services Inc. 2009. “Everything you want is there': The Place of the Reserve in First Nations' Homeless Mobility." Urban Geography 30 (4): 1-29. 
Peters, E. J. and O. M. Starchenko. 2005. "Changes in Aboriginal Settlement Patterns in Two Canadian Cities: A Comparison to Immigrant Settlement Models." Canadian Journal of Urban Research 14 (2): 315-37.

Prentice, S. 2007. "Childcare, Justice and the City: A Case Study of Planning Failure in Winnipeg." Canadian Journal of Urban Research 16 (1): 92-108.

Ponting, R. J. and C. Voyageur. 2001. "Challenging the Deficit Paradigm: Grounds of Optimism Among First Nations in Canada." Canadian Journal of Native Studies 21 (2): 275-307.

Raising the Roof. 2004. Youth Homelessness in Canada: The Road to Solutions. Toronto: Raising the Roof.

Richards, J. 2001. Neighbours Matter: Poor Neighbourhoods and Urban Aboriginal Policy. C. D. Howe Institute Commentary 156. Ottawa: C.D. Howe Institute.

Ruttan, L., P. Laboucane-Benson, and B. Munro 2008. “'A story I never heard before’: Aboriginal Young Women, Homelessness and Restorying Connections." Pimatisiwin: A Journal of Aboriginal and Indigenous Community Health 6 (3): 31-54.

- - - 2010. “'Home and Native Land': Aboriginal Young Women and Homelessness in the City." First Peoples Child \& Family Review 5 (1): 67-77.

Saskatoon Housing Coalition. 2008. Homelessness and Housing in Saskatoon. Accessed 10 March 2012. http://www.saskatoonhousingcoalition.ca/uploads/ saskatoonhomelesssurvey2008.pdf

Saul, J. R. 2008. A Fair Country: Telling Truths About Canada. Toronto: Viking Canada.

Segaert, A. 2011. "A Benchmark for Research into the Canadian Homeless Population." National Housing Research Committee Newsletter, Fall 2011: 11.

Serge, L. 2005. Transferability of the "Safe In the City" Approach to Youth Homelessness in Prevention in Canada. Ottawa: Canada Mortgage and Housing Corporation.

Siggner, A. J. and R. Costa. 2005. Aboriginal Conditions in Census Metropolitan Areas, 1981-2001. Ottawa: Statistics Canada.

Sider, D. 2005. A Sociological Analysis of Root Causes of Aboriginal Homelessness in Sioux Lookout, Ontario. Toronto: The Canadian Race Relations Foundation.

Skelton, I. 2002. "Residential Mobility of Aboriginal Single Mothers in Winnipeg: An Exploratory Study of Chronic Moving." Journal of Housing and the Built Environment 17 (2): 127-44.

Snow, D. 2008. A Roof Over Our Heads 2008: Affordable Housing and Homelessness Policy in Canada. Calgary: CanadaWest Foundation

Stanger-Ross, J. 2008. "Municipal Colonialism in Vancouver: City Planning and the Conflict over Indian Reserves, 1928-1950s." The Canadian Historical Review 89 (4): 541-80. http://dx.doi.org/10.3138/chr.89.4.541

Stewart, P. 2007. "Without a Place." The Canadian Architect 52 (3): 15. 
Stewart, C. J. \& Samantha Ramage. 2011. A Pan-Northern Ontario Inventory of Homelessness Problems and Practices: Position Paper. Northern Ontario Service Deliverers Association. Accessed Febuary 5, 2013. http://www.omssa.com/lib/ db2file.asp? file $=37101$.

Sookraj, D., P. Hutchinson, M. Evans, M. A. Murphy, and The Okanagan Urban Aboriginal Health Research Collective. 2010. "Aboriginal Organizational Response to the Need for Culturally Appropriate Services in Three Small Canadian Cities." Journal of Social Work, November 22: 1-22. http://dx.doi. org/10.1177/1468017310381366

Taefi, N. and A. Czapska. 2007. "Girl Homelessness in Canada." Parity Magazine, February. Accessed February 5, 2013. http://www.justiceforgirls.org/publications/ pdfs/ParityArticle.pdf

Thurston, W. and C. Mason. 2010. Aboriginal Homelessness Research: The Context, What We're Doing, and the Future. Accessed 3 March 2012. http://calgaryhomeless.com/ assets/research/Aboriginal-HomlessnessWThurstonCMason.pdf.

Waldram, J. B. 1990. "Access to Traditional Medicine in a Western Canadian City." Medical Anthropology 12: 325-48. http://dx.doi.org/10.1080/01459740.1990.99660 29

Walker, R. C. 2005. "Social Cohesion? A Critical Review of the Urban Aboriginal Strategy and its Application to Address Homelessness in Winnipeg." Canadian Journal of Native Studies 25 (2): 395-416.

- - - 2006. "Interweaving Aboriginal/Indigenous Rights with Urban Citizenship: A View from the Winnipeg Low-Cost Housing Sector, Canada." Citizenship Studies 10 (4): 391-411. http://dx.doi.org/10.1080/13621020600858096

Weasel Head, G. 2011. “'All We Need is Our Land': An Exploration of Urban Aboriginal Homelessness.” M.A. thesis, University of Lethbridge.

Wellesley Institute. 2010. Precarious Housing in Canada. Toronto: Wellesley Institute.

Wente, M. 2000. Urban Aboriginal Homelessness in Canada. Toronto: Faculty of Social Work, University of Toronto.

Westerfelt, A. and M. Yellowbird. 1999. "Homeless and indigenous in Minneapolis." In Voices of First Nations People: Human Services Considerations, ed. H. N. Weaver, 145-62 .New York: The Haworth Press, Inc.

Whitbeck, L. B., Y. Mansoo, K. D. Johnson, D. R. Hoyt, and M. L. Walls. 2008. "Diagnostic Prevalence Rates from Early to Mid-Adolescence among Indigenous Adolescents: First Results from a Longitudinal Study." Journal of the American Academy of Child and Adolescent Psychiatry 47 (8): 890-900. http://dx.doi.org/10.1097/ CHI.0b013e3181799609 
Whitbeck, L.B., G. W. Adams, D. R. Hoyt, and X. Chen. 2004. “Conceptualizing and Measuring Historical Trauma Among American Indian People.” American Journal of Community Psychology 33 (3/4): 119-30. http://dx.doi.org/10.1023/ B:AJCP.0000027000.77357.31

Williams, J. C. 2011. “'Stand Up and Be Counted': The Politics of a Homeless Enumeration." Poverty and Public Policy 3 (4): 1-27. http://dx.doi. org/10.2202/1944-2858.1172

Wilson, K. and E. J. Peters. 2005. “'You Can Make a Place for It': Remapping Urban First Nations Spaces of Identity." Environment and Planning D: Society and Space 23 (3): 395-413. http://dx.doi.org/10.1068/d390

Windsor, J. E. and J. A. Mcvey. 2005. "Annihilation of Both Place and Sense of Place: The Experience of the Cheslatta T'En Canadian First Nation within the Context of Large-Scale Environmental Projects.” The Geographical Journal 171 (2): 146-65. http://dx.doi.org/10.1111/j.1475-4959.2005.00156.x

Wood, P. K. 2003. "A Road Runs Through It: Aboriginal Citizenship at the Edge of Urban Development." Citizenship Studies 7 (4): 463-79. http://dx.doi. org/10.1080/1362102032000134985 